110-2019

Abs di Proceedings con peer review

Bollini, L. (2019). Dyslexia and Typography: how to improve educational publishing for inclusive design. A critical review. In L. Gómez Chova, A. López Martínez, I. Candel Torres. (Eds.). EDULEARN19 Proceedings. (p. 224). Lisbona: IATED Academy

[ISBN: 978-84-09-12031-4 ISSN: 2340-1117] 


\title{
DYSLEXIA AND TYPOGRAPHY: HOW TO IMPROVE EDUCATIONAL PUBLISHING FOR INCLUSIVE DESIGN - A CRITICAL REVIEW
}

\author{
L. Bollini \\ University of Milano-Bicocca (ITALY)
}

\begin{abstract}
In an educational system still widely based on textual information, books, and writing tasks dyslexia is one of the difficulties that some students face during the school years.

Dyslexia is commonly considered a complex learning disability affecting reading and writing performances, in particular, the way people interpret words, letters, and other symbols. Nevertheless, it doesn't influence general intelligence.
\end{abstract}

Different studies underline how it depends on various factors both genetic and environmental, often connected with other conditions such as ADHD, dyscalculia or dysgraphia.

According to Firth, reading and writing skills are learned using three different strategies respectively based on logographic, alphabetical and orthographic abilities. In the last case, the more complex, the text is analyzed as a string of specific letters and the sense is independent of the context.

On the other hand, writing is the visual translation of linguistic signs through conventional graphic representation with shared meanings.

Therefore, human beings approach reading from childhood, learning to see means, being able to recognize the shapes of letters drawn on a sheet of paper or a digital display and give them a meaning. The perception of the letters and the comprehension of the message encoded by them refers both to readability and legibility concepts.

In particular, legibility is related to the visual perception of a text and the ability to distinguish a single character.

In the last few years, different experiments have been conducted to understand which fonts were more legible or helpful for dyslexic people and how to improve their learning abilities. Besides, under a more inclusive mindset, some designers have tried to draw and implement more accessible fonts, and some educational publishers have included the issue in their editorial process.

The paper presents and discusses the more significant research projects, proposing a critical comparison of the more relevant experimental findings, the limits of the outcomes and which seem to be the best legible fonts.

Keywords: Dyslexia and Typography, Font design, educational publishing, Design for all, Universal design. 